\title{
Mácocael, la roca sagradla de los aborígenes
}

\section{Mácocael, The Sacred Rock Of The Aborigines}

José Eusebio Chirino Camacho ${ }^{1}$, Adilson Tadeu Basquerte ${ }^{2}$, Eduardo Pimentel Menezes ${ }^{3}$

\section{RESUMO}

Cuando el 24 de octubre de 1968, descubrimos para la ciencia, la Gruta de los Huesos, en lo alto del Peñón del Indio como le llamaban en aquella época al mogote cársico el que; por sus características morfológicas siempre vimos como algo distinto. El descubrimiento en la Peña del Indio en Cedeño Jobo Rosado, de un enterramiento representado por huesos fragmentados y dientes humanos, constituyó en su momento un enigma para la Arqueología. Las excavaciones y posteriores estudios mostraron una nueva forma de rito funerario a lo que José Chirino denominó, "enterramiento residual". Luego de varias visitas al pie del Peñón, no fue que, hasta la década del 90 del Siglo XX, se pudiera observar desde cierta distancia que el promontorio pétreo tenía semejanza con un rostro antropomorfo natural. A partir de ese momento, se rompió el enigma y nos dimos cuenta de que el proceso ritual funerario respondía a una creencia, una deidad para los aborígenes quienes le convirtieron en "Adoratorio", constituyendo desde entonces y hasta la actualidad el único sitio con esas características en Cuba y todo el Caribe Insular. Hoy se pone a disposición del Desarrollo Local, sobre todo en la rama del conocimiento.

Palavras-chave: Ritos funerarios, Adoratorio, Arqueología.

\section{ABSTRACT}

When on October 24, 1968, we discovered for science, the Grotto of the Bones, at the top of the Peñon del Indio, as the karst mogote was called at that time; Due to its morphological characteristics, we always saw it as something different. The discovery in the Peña del Indio in Cedeño Jobo Rosado, of a burial represented by fragmented bones and human teeth, constituted an enigma for archeology at the time. The excavations and subsequent studies showed a new form of funeral rite to what José Chirino called, "residual burial". After several visits to the foot of the Rock, it was not that, until the 90s of the 20th century, it could be observed from a certain distance that the rocky promontory resembled a natural anthropomorphic face. From that moment, the enigma was broken and we realized that the funeral ritual process responded to a belief, a deity for the aborigines who turned it into an "Adoratory", constituting from then until today the only place with these characteristics in Cuba and the entire Insular Caribbean. Today it is made available to Local Development, especially in the branch of knowledge.

Keywords: Funeral rites; Shrine, Archeology.

\footnotetext{
${ }^{1}$ Centro de Servicios Ambientales de Sancti Spíritus. CITMA. Yaguajay, Sancti Spíritus, Cuba. E-mail: joseeusebiochirino@gmail.com.

${ }^{2}$ Doctor en Geografía. Profesor en el Centro Universitário Para o Desenvolvimento do Alto Vale do Itajaí (UNIDAVI). abasquerote@ yahoocom.br.

${ }^{3}$ Doctor en Geografía y en Educación. Profesor Asociado (UERJ y PUC/RJ). epemenezes30@gmail.com.
} 


\title{
INTRODUÇÃO
}

\begin{abstract}
"De qué parte han venido los indios y en qué modo: La española, tiene una provincia llamada Caonao en la que está una montaña que se llama Cauta, que tiene dos cuevas nombradas Cacibajagua una y Amayauna la otra. De Casibajagua salió la mayor parte de la gente que pobló la isla. Esta gente, estando en aquellas cuevas, hacía guardia de noche y se había encomendado este cuidado a uno que se llamaba Mácocael; el cual, porque un día tardó en volver a la puerta, dicen que se lo llevó el Sol. Visto, pues, que el Sol se había llevado a este por su mala guardia, le cerraron la puerta; y así fue transformado en piedra cerca de la puerta. (Fray Ramón Pané, "Relación acerca de las antigüedades de los indios. Capitulo I, 1990. p.24).
\end{abstract}

Todo comenzó cuando el priemer autor, José E. Chirino Camacho era maestro de primaria. Comenzaría, sin saberlo en él, una nueva vocación. Asi, un día de principios de Octubre de 1968, durante las clases, un alumno informó al maestro de la existencia en la región, de un peñón que nombraban en la zona de Cedeño, "La Peña del Indio", en el límite Norte del pobladito de Vicente Pis (donde se encontraba la escuela) con Jobo Rosado, actualmente es jurisdicción del municipio Yaguajay, norte de la provincia de Sancti Spíritus, Cuba.

Ya en la tarde se fue al peñón, pero solo se pudo ver allí la existencia de cuevas laberínticas en las que se adentraron muy poco por falta de luz. Por no poner en peligro al niño, se desistió de continuar revisando y se salió del lugar. En Octubre, trasladado el autor de referencia a la zona del Rincón, lugar al que se iba a pie desde Vicente Pis, había que atravesar las alturas pétreas de la Sierra de Matahambre y bajar por el paraje llamado Las Cuevas. Allí, al pie de un enorme peñón, vivía el campesino Evaristo Acevedo, con el que cada día, de ida o regreso, se conversaba de diferentes temas.

Un día, el viejo Evaristo - quizás confiando en los conocimientos del maestro manifestó que, a criterio suyo, al pie de su peña, en épocas de la guerra de independencia, había trabajado allí un dentista, porque aparecían muchas piezas dentarias a simple vista.

Se hizo una incursión al lugar el veintitrés de Octubre de ese año, y en efecto, allí aparecían cientos de piezas dentales pero, con la característica de que no presentaban caries y si, ciertos desgastes que resultaban algo raro para el maestro. Las piezas, de todo tipo, estaban disgregadas por el piso seco, debido a que, en esa área, el propio alero cársico, no permite que la lluvia llegue nunca. Lo que, por lógica, habían aprovechado los que dejaron aquellos restos humanos en el lugar. 
Sin saberlo, en pocos días se habían descubierto los primeros dos sitios arqueológicos en tierra firme en el territorio municipal de Yaguajay y comenzaba además una carrera interminable en la existencia del autor: "Arqueólogo"; condición que se ha podido alcanzar después de más de 50 años de experiencia directa en el estudio de decenas de sitios que fueron apareciendo y estudiando posteriormente en Cuba y otros países de América.

El descubrimiento del sitio en la Peña de Evaristo, provocó el entusiasmó a hacer nuevas incursiones e investigar más con los adultos de la zona sobre El peñón del Indio en Cedeño, y así, se logró contactar con el campesino Alberto Morichal Cáceres, quien, al día siguiente (24 de Octubre de 1968), guió al principiante arqueólogo, a lo que ellos llamaban la gruta de los huesos, en una casi inaccesible oquedad en la propia roca, a más a de quince metros de altura, donde para su asombro, aparecieron cientos de fragmentos de huesos. El descubrimiento de lo que hoy se ha denominado sitio funerario "la Gruta de los Huesos" en el lugar conocido como Peñón del Indio, o "Mácocael”, en Yaguajay, pasó como un hecho sin relevancia hasta los años ochenta del siglo $\mathrm{XX}$, en que, en compañía de algunos miembros del Grupo Espeleológico Caguanes se realizaron las primeras prospecciones dirigidas por el autor que comenzaron a aportar datos y se fue conformando la hipótesis de que se trataba de un sitio funerario con características muy singulares comparado a los reportados hasta ese momento en Cuba. La Figura 1, presenta Peñón del Indio, o Mácocael, con su rosto de piedra.

Figura 1- El rostro de piedra a distancia, como debieron descubrirlo los aborígenes.

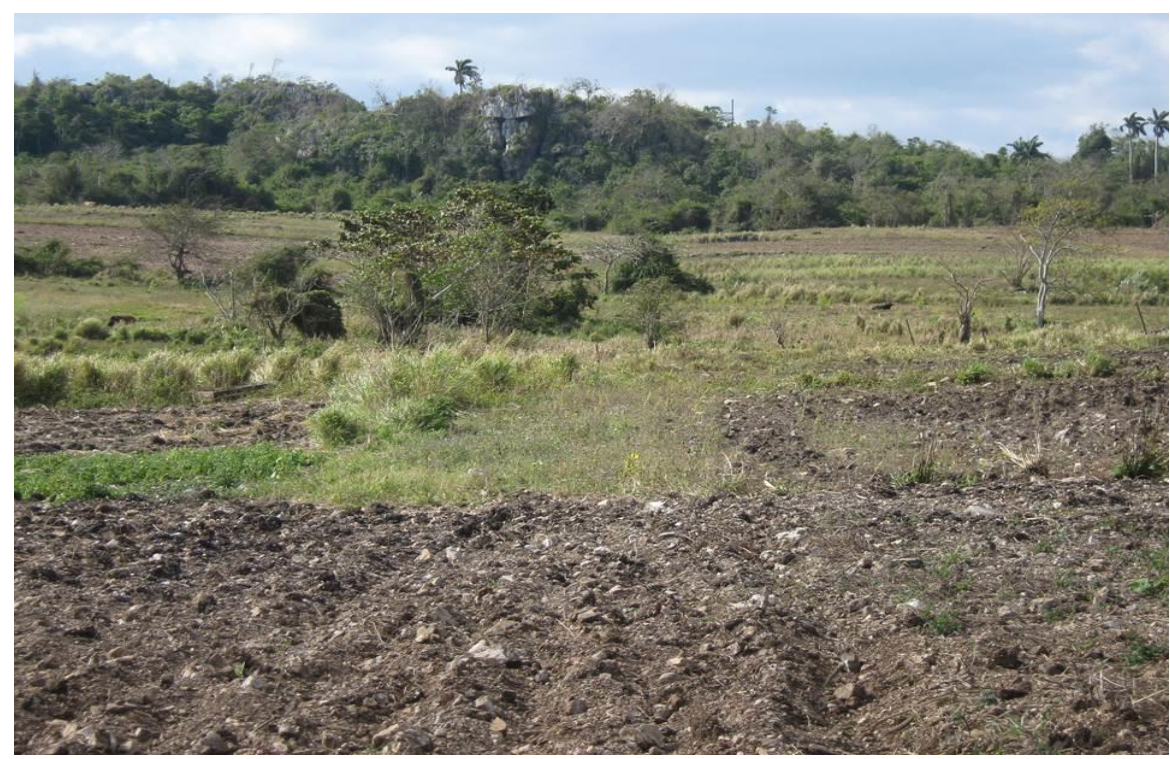

Fuente: preparado por los autores (2021). 
Durante el 2do. Encuentro Nacional de Arqueología Aborigen, en abril de 1992, fue presentado por el primer autor, un trabajo preliminar, en el que se informaba del hecho y se planteaban los siguientes criterios en el Cuadro 1:

Cuadro 1- Critérios planteados

\begin{tabular}{|c|l|}
\hline \multirow{3}{*}{ Critérios } & $\begin{array}{l}\text { Que se trataba de un enterramiento de tipo RESIDUAL en el que existían restos de } \\
\text { varios individuos, aparentemente llevados al lugar en forma de rito u ofrendas, tales } \\
\text { restos habían sido fracturados a propósito por quienes los depositaron en el sito. }\end{array}$ \\
\cline { 2 - 2 } & $\begin{array}{l}\text { Que de ser así, podría constituir, por esas características, el reporte de un nuevo tipo } \\
\text { de enterramiento para la Arqueología cubana }\end{array}$ \\
\hline
\end{tabular}

Fuente: preparado por los autores (2021).

El informe fue objeto de fuertes y fructíferos análisis por parte de los participantes en aquel importante evento entre los que se encontraban presentes el Dr. C. Antonio Núñez Jiménez y el Dr. C. Manuel Rivero de la Calle. Fue entonces que surgió la idea de realizar un estudio más profundo que demostrara con argumentos científicos bien fundamentados, tales previsiones, las que correspondían a las apreciaciones de colectas y exploraciones de campo.

De esa forma, se coordinó con el Dr. Manuel Rivero de la Calle Antropólogo Físico; Profesor Titular y Emérito de la Universidad de la Habana, y el Dr. Luis R. Toribio Suárez, Odontólogo Forense de la propia Universidad, para los análisis antropológicos de laboratorio; dichos estudios, debían aportar los datos científicos suficientes para llegar a conclusiones sobre tan importante descubrimiento. Pasaron años con los resultados engavetados. Pero, en el 2019, se presenta como investigación concluida al Fórum de Ciencia y Técnica de la Sede universitaria "Simón Bolívar" de Yaguajay (Universidad provincial José Martí de Sancti Spíritus). Obtuvo la condición de RELEVANTE y se acordó, convertirle en un artículo para que fuera publicado.

Para el desarrollo de esta investigación, se trazaron los siguientes objetivos: El objetivo general era presentar por primera vez la investigación en un Fórum de Ciencia y Técnica de la Sede del Centro Universitario Municipal y para contribuir al Desarrollo Local de Yaguajay en la rama del conocimiento; informando sobre los valores históricos de este sitio arqueológico y, además, exponer los aportes científicos que de ello se derivan.

Además, de los objetivos específicos presentados se destaca: 1- Realizar una profunda prospección arqueológica acompañada de un trabajo de excavación y rescate de 
todo el material arqueológico de la pequeña gruta, de, con el fin de valorar las características del sitio y extraer todo el material existente, incluyendo el levantamiento topográfico y cartográfico del lugar.

2. Desarrollar clasificación previa y estudios de gabinete y laboratorio desde el punto de vista antropológico físico, al material dental y óseo, con el fin de poder determinar: cantidad de individuos, edades, sexo, etc. Presentes en el fracturado del material.

3.Desarrollar un estudio de determinación de elementos traza en dientes mediante espectrometría de absorción atómica para establecer fuentes alimentarias y conocer posible presencia de uno o más estadios de desarrollo humano presentes en el municipio, representados en el enterramiento.

\section{MÁCOCAEL, LA ROCA SAGRADA DE LOS ABORÍGENES: Informe de la labor arqueológica del arqueólogo José E. Chirino Camacho}

Ubicado según las coordenadas Geodésicas, el sitio se puede localizar en el mapa 1:50 000 del I.C.G.C, Hoja Yaguajay 4382-1 coordenadas: X268-80 Y685-30 y según la ubicación del G.P.S (Sistema de Posicionamiento Global) se encuentra en los $22^{\circ} 14^{\prime}$ $30,89508^{\prime \prime}$ y $\operatorname{los} 79^{\circ} 12^{\prime} 8,61404 "$ ", a una altura de $256 \mathrm{~m}$. sobre el nivel del mar (CHIRINO, 2010).

En ellla, los trabajos de campo se llevaron adelante, durante los años de 1981, 1993 y 1994 y durante 1995, los de laboratorio antropológico de la Universidad de La Habana y en 2016, los estudios de traza en dientes en la Facultad de Química de la Universidad Martha Abreu de Santa Clara, Villa Clara. Hoy, luego de grandes esfuerzos, podemos presentar, al fin, un informe científico de los resultados, aunque ha sido imposible por el momento realizar el fechado absoluto, labor que podrá demorar un tiempo. Por la aparente diversidad de edades de los huesos no es posible, ofrecer cálculos preliminares por el método del fechado relativo.

De manera mas detallada, durante el mes de Enero de 1993, se recomenzaron los trabajos arqueológicos de campo (sobre los que ya existían algunos datos aportados por varias expediciones como ya se ha expuesto antes), entre 1980 y 1982 por el grupo espeleológico Caguanes y entre 1988 y 1990, por el autor primer autor con otros colaboradores. 
En 1994, se visita de nuevo el lugar y se procede, aplicando métodos adecuados de prospección, que incluyeron un estudio histórico-geográfico de la zona, el que comenzó con la bibliografía existente, comprobaciones de testimonios y antevistas a campesinos pobladores del lugar para conocer las trasmisiones orales sobre el asunto objeto de estudio.

Análisis de las características geológicas, geomorfológicas, del paisaje y biológicas del área, hasta la medición topográfica y dibujo cartográfico del mogote cársico, en especial la gruta (comprobando dirección, altura etc.) Con anterioridad se había explorado la zona y se pudo comprobar, solo la existencia del sitio funerario primario Peña de Evaristo, a tres km del lugar en dirección Este, excavado por Alfredo Rankin Santander y José E. Chirino Camacho, en unión al grupo Espeleológico Caguanes en 1982, con una edad relativa aproximada entre los 1200 +- 900 AP. Comprobándose la no existencia de sitios habitacionales a no menos de $7 \mathrm{Km}$. del peñón. La Figura 2, presenta el perfil topográfico de Penón.

Fugura 2- Perfil topográfico de Penón del Indio o Macacoel.

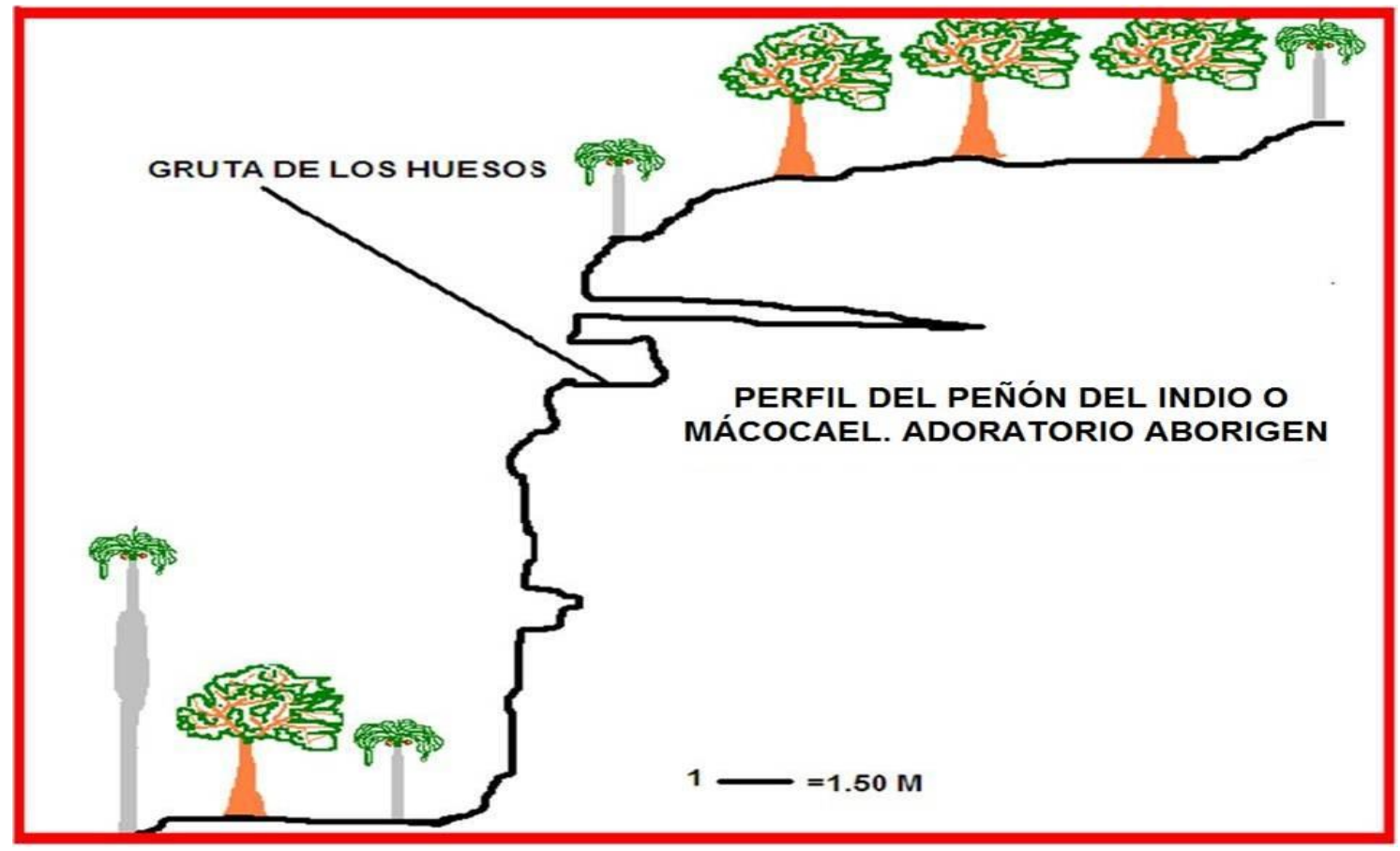

Fuente: Los autores (2021).

La fase de prospección arrojó los siguientes datos:

La zona objeto de estudio está comprendida en la Unidad Geotectónica Numero IV- Cuencas Superpuestas: Los sedimentos de cuencas superpuestas en el municipio supra yacen a las rocas de la Plataforma de las Bahamas y se localizan en los alrededores 
de Mayajigua, Jobo Rosado. Esta asociación surge durante el hundimiento y plegamiento de la corteza Terrestre. La aparición de abruptas cuencas marinas y la deposición sedimentaria de un intenso aporte terrígeno durante su desarrollo. Está representada por las unidades litográficas con edades que varían desde el Paleoceno, hasta el Eoceno superior (60-40 000000 de años). (1).

Desde el punto de vista Geomorfológico, se define la zona así: (2) Estas sierras están formadas por una serie de elevaciones calcáreas margosas de unos 300m, que aumentan su altura hacia el Este e incluyen valles cársicos alargados y extensas superficies planas en el W y centro; pequeños mogotes y campos de lapié.

En relación con el paisaje, este se describe como cimas calcáreas de mas de 300m, de altura con suelos esqueléticos muy pedregosos con pastos y restos de bosques semideciduos degradados.

Aun la zona presenta cierta naturalidad y belleza en su conjunto paisajístico, el que por la altura del mogote, se presenta muy atractivo al hombre actual - quizás estas características, debieron atraer al aborigen hasta allí (CHIRINO, 2010).

Como se informó antes, el mogote ha tenido a lo largo de la historia varias denominaciones: Cueva del Indio o Peñón del Indio desde siglos pasados y los pobladores no conocen otras evidencias de presencia aborigen allí, que no sean la historia de los huesos que han aparecido en el lugar. La locación objeto de estudio constituye un mogote cársico (como ya hemos explicado) de alrededor de $27 \mathrm{~m}$. de altura en su pared NE, desde la base. La gruta de los huesos es una pequeña oquedad que mide $8 \mathrm{~m}$ de largo por $2 \mathrm{~m}$ de ancho y $2.50 \mathrm{~m}$ de alto. De origen eólico, presenta la forma de túnel con una entrada principal de muy difícil acceso y una que da al precipicio. Se encuentra a $15 \mathrm{~m}$. de altura de la base del mogote (ver perfil anexo), desde ambas aberturas, brinda un amplio panorama que alcanza hasta el mar y los cayos. Está dirigida E-NW y se comprobó además que no está directamente en la figura, sino al lado de la misma como respetando el espectro o aparente ídolo de origen natural.

El suelo pétreo, presenta un relieve que se denota con poco desnivel y las paredes, muy lisas, dan la impresión de que fuera creada intencionalmente como una cripta a la que le penetran los rayos del Sol del amanecer hasta después de las $10.40 \mathrm{am}$, como puede ser visto en la Figura 3: 
Figura 3- La figura humana sobre el peñón y la flecha marcando la Gruta de Los Huesos, ofrece una idea de la dimensión del adoratorio.

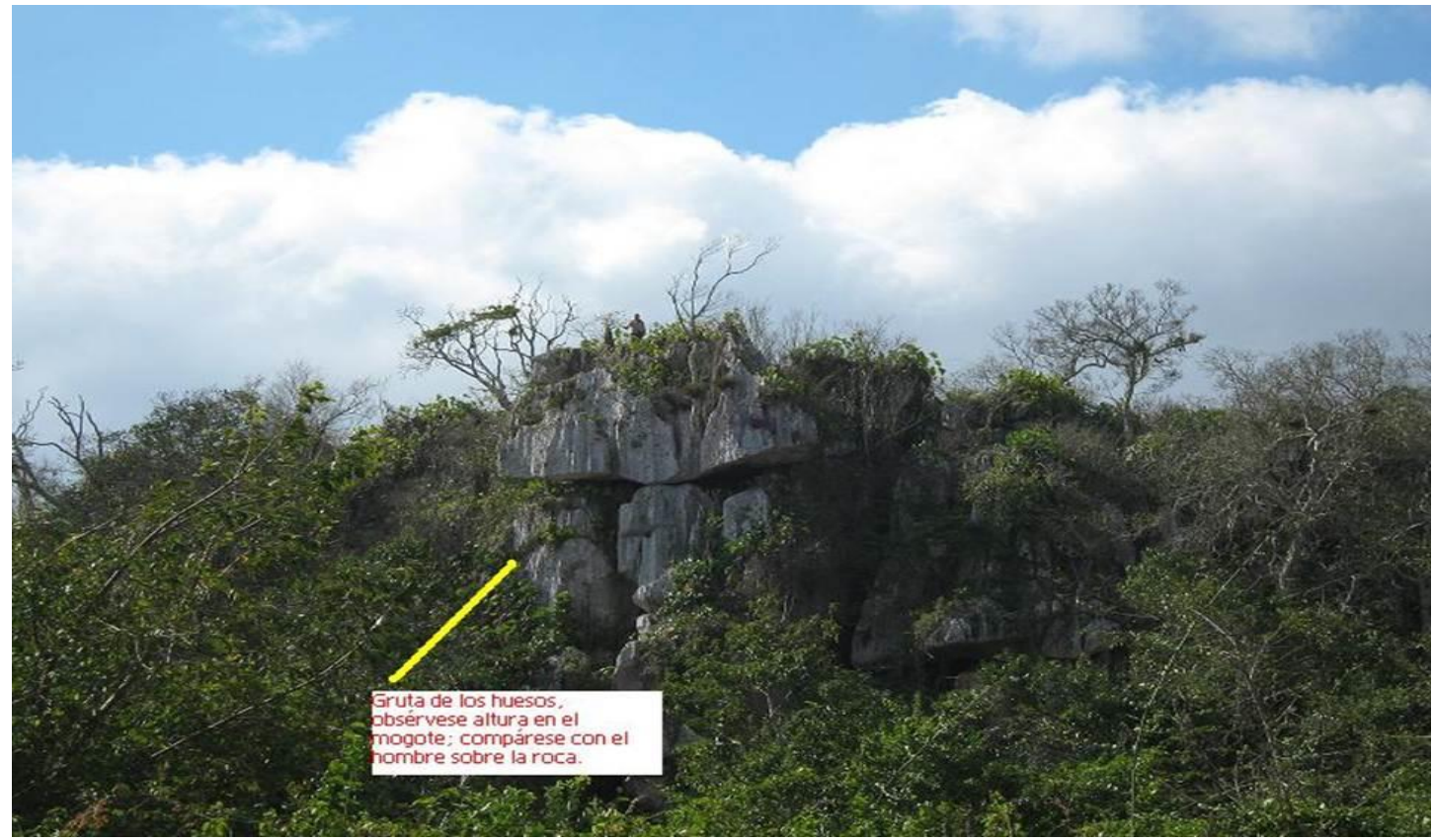

Fuente: Los autores (2021).

\section{INFORME DE LA ACTIVIDAD ARQUEOLÓGICA: EXCAVACIÓN Y CLASIFICACIÓN DEL MATERIAL OBTENIDO}

Luego de los estudios en relación con la zona, se procedió al desarrollo y ejecución de una excavación, precedida por un levantamiento topográfico del sitio a excavar. Estas labores que se desarrollaron en tres jornadas de un día cada una, fueron dirigidas por el primer autor y en ella participaron indistintamente los colaboradores siguientes: Eduardo Guevara Sánchez, Armando Falcón Méndez, Carlos Rojas Guerra, Maithe Cardoso Padrón, Maida Abella Carrazana, Ángel M. Martínez Gómez, Elier Sánchez Díaz y Javier Romero Calero.

Se excavó por el método del estrato natural, dado las características del suelo y llevando adelante un solo frente de excavación, continuo y no seccionado, pues el poco espacio a excavar así lo exigía, ajustándonos a los contornos de la gruta. Así, durante los trabajos de desenterramiento, se pudo observar que, el suelo que excavábamos, era el producto de sedimentos de materia orgánica y otros elementos que fueron acumulándose 
luego de haber sido depositados los restos óseos fracturados y las piezas dentales sobre el pétreo piso sin cubrir con otro material alguno.

En la medida en que se adelantó en las excavaciones, fueron apareciendo indistintamente, de manera arbitraria y en grandes cantidades, fragmentos de diferentes huesos humanos y piezas dentales, las que por su morfología informaban de la presencia en los restos, de varios individuos de diferentes edades. En las partes más profundas, se encontraron la mayor cantidad de huesos humanos. El material extraído fue pasado por un tamiz de $0.3 \mathrm{~cm}$, lo que permitió la recopilación de todo el entierro, incluyendo piezas dentales de niños de muy corta edad. En la medida en que las circunstancias lo permitieron se hicieron fotos, algunas de las cuales se presentan en la Figura 4.

Algo llamó la atención desde el principio y fue la altura a partir de la base en que se encuentra la gruta, su difícil acceso y en especial, aunque aparecieron algunas piedras calizas, fragmentos de sílex, caracoles del molusco Ligus sp. Por su situación en superficie (aparentemente no puestas a propósito), fue la falta total de ofrendas y otras piezas asociadas, lo que nos hizo inferir que los propios restos constituyeron la ofrenda en un ritual desconocido hasta entonces para la Arqueología cubana (CHIRINO, 2010). Inmediatamente se procedió a la limpieza y clasificación preliminar del material que arrojó los resultados presentados en el Cuadro 2:

Cuadro 2- Resultado prelimenares de las excavaciones.

\begin{tabular}{|c|c|}
\hline \multirow{8}{*}{ Resultados } & $\begin{array}{l}\text { Total ausencia de otro material arqueológico que no sean los fragmentos de } \\
\text { huesos y piezas dentales. }\end{array}$ \\
\hline & $\begin{array}{l}\text { Los dientes de los individuos adultos presentan los desgastes de las cúspides } \\
\text { peculiares en los aborígenes; aunque en algunos, este desgaste es muy } \\
\text { pronunciado. }\end{array}$ \\
\hline & $\begin{array}{l}\text { Los restos más conservados de cráneos que aparecen, se encuentran entre los } 5 \\
\text { y } 15 \mathrm{~cm} \text {. de la entrada principal de la cripta (dirección E). }\end{array}$ \\
\hline & $\begin{array}{l}\text { En ningún caso aparecen restos óseos completos y se encuentran mezclados } \\
\text { huesos de individuos adultos, jóvenes y niños; entre estos últimos hasta de muy } \\
\text { temprana edad. }\end{array}$ \\
\hline & De igual modo sucede con las piezas dentales. \\
\hline & $\begin{array}{l}\text { Aunque estas, aparecen en su mayoría en buen estado, hay varias fracturadas. } \\
\text { Supuestamente a propósito. }\end{array}$ \\
\hline & $\begin{array}{l}\text { Se evidencia en los restos óseos la fracturación intencional, por medio de golpes, } \\
\text { antes de depositarlos en el lugar. }\end{array}$ \\
\hline & $\begin{array}{l}\text { Todo el material se encuentra diseminado por el área, salvo algunos "paquetes" } \\
\text { o grupos casi compactos que aparecieron en las partes más profundas del relieve } \\
\text { en el estrato natural de la excavación. }\end{array}$ \\
\hline
\end{tabular}

Fuente: Preparado por los autores (2021). 
Como resultado de la clasificación en gabinete o por observación, se identificaram diferentes materiales: Fragmentos de huesos humanos, Piezas dentales, Fragmentos de piedra caliza, Fragmentos de silex y Caracoles de la especie Ligus sp. El Cuadro 3 presenta los materiales encontrados y su cantidad.

Cuadro 3-. Materiales encontrados en el área de estudio por cuntidad.

\begin{tabular}{|l|c|}
\hline \multicolumn{1}{|c|}{ Materiales } & Cantidad \\
\hline Fragmentos de huesos humanos & $1386^{4}$ \\
\hline Piezas dentales & 58 \\
\hline Fragmentos de piedra caliza & 7 \\
\hline Fragmentos de sílex & $6^{5}$ \\
\hline Caracoles de la especie Ligus sp & 3 \\
\hline
\end{tabular}

Fuente: Preparado por los autores (2021).

Lo que se observa es una gande cantidad de huesos, totalmente fracturados pudieran brindar la posibilidad de determinar una sola persona. Nótese en la Figura 4, captada en por el primer auto en 1995, huesos y las piezas dentales puestas también en el piso de la oquedad.

Figura 4 - Huesos y las piezas dentales encontrados en Macacoel.

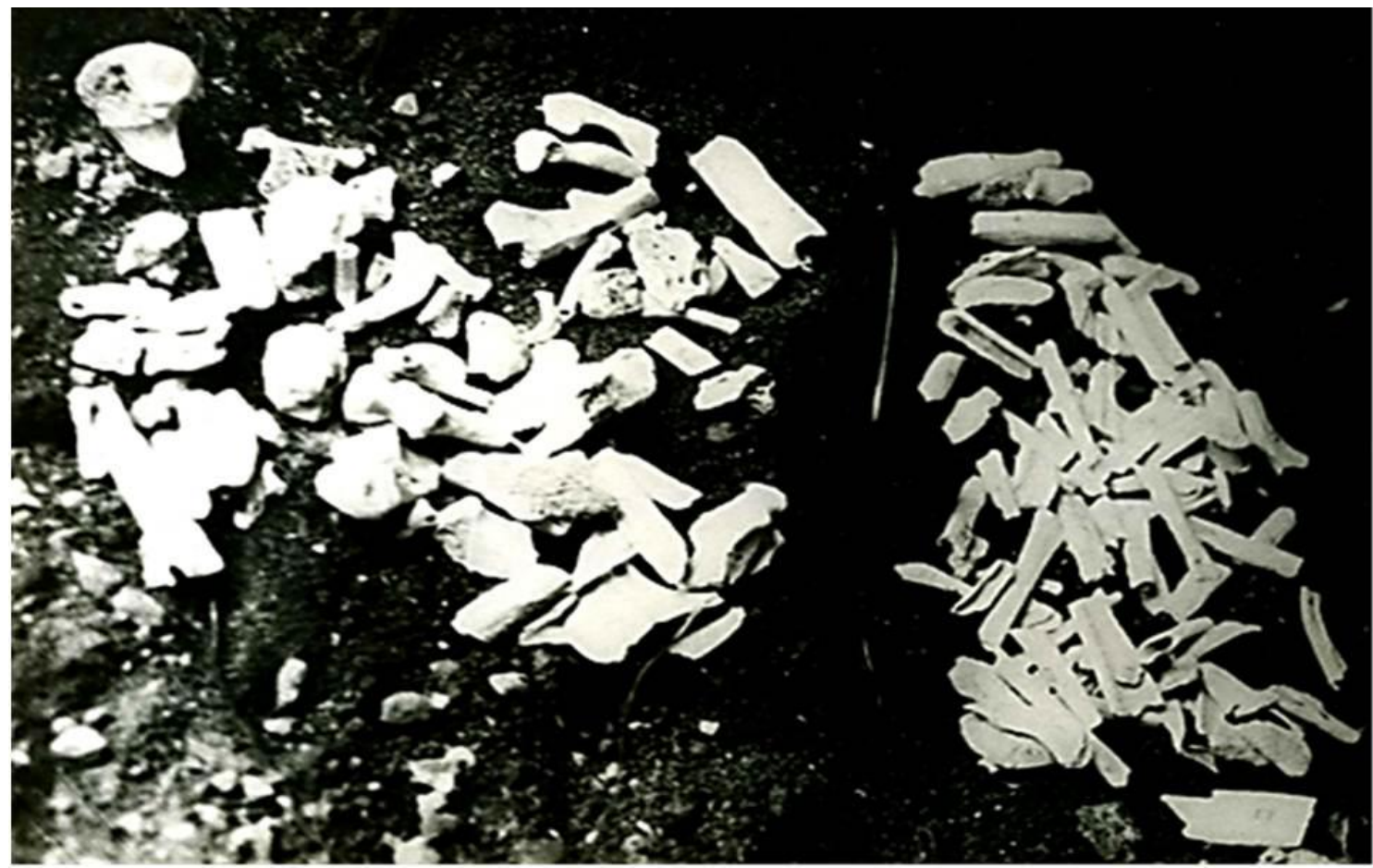

\footnotetext{
${ }^{4}$ Es importante destacar, que no fue posible desde el punto de vista arqueológico, hacer la clasificación de los restos por el estado fragmentario en que se encuentran.

${ }^{5}$ Los fragmentos de sílex debieron haber sido llevados por los aborígenes, los de piedra caliza pueden ser de la propia roca del peñón y los caracoles son del área, los que pudieron caer a la oquedad de forma natural con el tiempo.
} 
Fuente: Arquivo personal de primer autor (1995).

Sobre el informe y análisis de laboratorio, desde el punto de vista antropológico físico y forense, se destca el Estudio de laboratorio antropológico, por los Dres. Manuel Rivero de la Calle (el material óseo) y Luis R. Toribio Suárez (las piezas dentales).

Así, como resultado das análisis al material dental realizados por el Dr. Luis R. Toribio Suárez, resultó en el informe sobre la estimación del $n^{\circ}$. de enterramientos de la Gruta de los Huesos:

I- Clasificación: Se logró clasificar 58 dientes, de los cuales 3 eran temporales; en algunos casos no fue posible establecer exactamente de qué dientes se trataba debido al mal estado (fracturas principalmente) en que se encontraban. El deterioro impidió realizar los estudios odontoscópicos y odontométricos. La estimación de la edad de los individuos representados por los dientes, se hizo atendiéndose al grado de calcificación de los órganos dentarios y cuando esta, ya había concluido, por el grado de abrasión observando las coronas.

II- El método seguido permite establecer estimaciones que subestima generalmente el No. Real de enterramientos y no debe en promedio subestimarlo. -Cuanta mayor información morfológica se utilice, el nivel de sub-estimación es menor acercándose más de esta manera, al valor del parámetro. (Entiéndase en este caso la población como la representada por dientes recolectados).

III- Estimación: Se hizo atendiendo a la clasificación morfológica de los dientes y a la estimación de la edad. Se logró estimar que, al menos fueron enterrados 15 individuos. De ellos con la estimación de la edad, fue suficiente para establecer con 23 dientes la presencia de 11 individuos (sub-adultos). Sin embargo, 35 dientes de sujetos mayores de 20 años, solo permitieron identificar 4 individuos ya que únicamente nos pudimos basar en la repetición de dientes del mismo grupo, lugar: (maxilar o mandibular) y lado: (derecho o izquierdo).

IV- Hipótesis: Si el comportamiento de la relación $n^{\circ}$. de dientes- $n^{\circ}$ de enterramientos encontrados para los individuos menores de 20 años: 11 (individuos)/23 (dientes) $=0.478$ fuera semejante al de los individuos mayores de 20 años, habría que esperar la identificación de: 0.478 por $35=17$ individuos. Para así llegar a la estimación (donde cabe aun esperar una sub-estimación) de: 11+17=28 individuos- donde 11 individuos fueron estimados por el método directo y 17 por el método indirecto. 
El Cuadro 4, presenta la estructura de la población representada en los dientes según la edad por el Metodo Directo.

Cuadro 4 - Estructura de la población representada en los dientes según la edad por el Metodo Directo.

\begin{tabular}{|c|c|}
\hline \multicolumn{2}{|c|}{ MÉTODO DIRECTO } \\
\hline $\mathrm{N}^{\circ}$. de individuos & Edad estimada. \\
\hline 1 & $7 \mathrm{1} / 2$ AÑOS +- 9 meses \\
\hline 1 & 18 meses +-3 meses \\
\hline 1 & 6 meses +-2 años \\
\hline 1 & $10-20$ años \\
\hline 1 & $4-6$ años \\
\hline 1 & 9 meses +-2 meses \\
\hline 1 & 10 años +-9 meses \\
\hline 1 & 12 años +-6 meses \\
\hline 1 & 2 años +-6 meses \\
\hline 1 & $12-15$ años \\
\hline Total: 11 & $15-18$ años \\
\hline
\end{tabular}

Fuente: Preparado por los autores (2021).

Mediante el Método Indirecto, el estudio identificó un total de 17 individuos de diferentes edades. como se identifica en Cuadro 5.

Cuadro 5 - Estructura de la población representada en los dientes según la edad por el Metodo Indirecto

\begin{tabular}{|c|c|}
\hline \multicolumn{2}{|c|}{ MÉTODO INDIRECTO } \\
\hline $\mathrm{N}^{\circ}$. de individuos & Edad estimada. \\
\hline 4 & $20-25$ años. \\
\hline 10 & $>25$ años \\
\hline 3 & $>30$ años \\
\hline Total: 17 & - \\
\hline
\end{tabular}

Al final, se identificaron 11 individuos por el Método Directo y por el Método Indirecto 17, lo que resultó en un total de 28 individuos.

Por otro lado, los resultados del análisis del material óseo realizado por el Dr. Manuel Rivero de la Calle comprobó que el material óseo procedente de la Gruta de los Huesos en el Peñón del Indio de Cedeño, en Jobo Rosado, tiene como característica fundamental la gran fragmentación del mismo, lo que impide realizar un estudio antropológico detallado, ya que estamos no solamente ante un material muy fragmentario sino, también de poco tamaño. 
Además, los huesos largos, ya sea por la diáfisis o mitad de estas, habiéndose podido identificar tan solo dos fragmentos de húmero y también fue posible identificar un fragmento de cúbito. Como en otros entierros el material osteológico está representado en su mayoría, por huesos de cráneos, los que a pesar de su fortaleza aparecen aquí muy fragmentados, habiéndose hallado tan solo una porción donde se aprecian las áreas supraorbitarias y del reborde correspondiente. Este hecho, de las escasas piezas correspondientes a la zona supraorbitarias, que es muy fuerte, pudiera indicar la poca cantidad de individuos que están representados en este entierro según el material óseo.

Con respecto a los niños, estos se encuentran representados por un fragmento mandibular que posee un incisivo permanente en proceso de brote, un cuerpo vertebral, un fragmento de hueso largo y una rótula, así como un fragmento de epífisis H. J.

De los huesos de la bóveda, los fragmentos de occipital son los más abundantes, los que se han podido identificar por la presencia de las fases cerebrales y carabelosas. Igualmente los temporales se han identificado por la región petrosa y por la prebacia de cara lateral.

El hecho de que el número de individuos esté representado en una forma irregular, donde no hay correspondencia en cuento a la representatividad de unos huesos y otros, pueden indicarnos que el material fue depositado allí intencionalmente traído de uno o varios sitios no localizados, donde los huesos fueron recogidos al azar, fragmentados intencionalmente, dando lugar a un nuevo tipo de enterramiento dentro de las culturas aborígenes de Cuba. Además, la blancura que muestra la gran mayoría de las piezas, ya que tan solo algunas muestran un color gris, con una superficie algo alterada, hace pensar que este enterramiento procede de un mismo momento histórico.

Valdrá la pena realizar una pesquisa arqueológica para tratar de localizar el posible lugar de origen del material, si es que el mismo fue trasladado de otro lugar como es la opinión generalizadas de los investigadores o fragmentado en la misma cueva como parte de algún ritual, pero en ese caso habría de preguntarse ¿dónde se encuentra el resto del material?

\section{APORTE DE FRAGMENTOS IDENTIFICADOS:}

a) Húmeros - Fragmento distal de diáfisis de húmero izquierdo identificado con la letra "A", posee una longitud de $90 \mathrm{~mm}$ y diámetro transverso: máximo $20 \mathrm{~mm}$ y mínimo $18 \mathrm{~mm}$. El fragmento de diáfisis de húmero derecho identificado con la letra 
“B”, posee una longitud de $89 \mathrm{~mm}$ y diámetro transverso: máximo $22 \mathrm{~mm}$. Y mínimo 20 $\mathrm{mm}$. El fragmento "A” ofrece pequeñas diferencias en cuanto a los diámetros transversos máximos y mínimo al compararse con la "B", pues son más pequeños, pudiendo determinar corresponder a dos individuos distintos. Aunque la superficie de los huesos se encuentra ligeramente alterada, se puede observar el poco desarrollo de la tuberosidad bicipital, lo que sugiere la asignación del sexo femenino.

b) Comparando el cuerpo vertebral con uno correspondiente a un niño aborigen de 3 a 4 años, observamos cierta semejanza, aunque se tiene el inconveniente que el tamaño del cuerpo vertebral varía tanto por edad como por su posición en la columna vertebral.

c) En los huesos de la mano hay una predominancia de caracteres femeninos y corresponden al hueso grande, ganchoso y semilunar, habiéndose supuesto que corresponden a individuos adultos.

d) En cuanto a los metacarpianos adultos, hay presencia de ambos sexos.

e) Fragmentos mandibulares, uno izquierdo y el otro derecho, correspondientes al cuerpo de la mandíbula donde se observan restos suaves de la prominencia lateral externa en ambos sexos. Por tener un desarrollo similar, tentativamente se puede decir que corresponden a un mismo individuo. El ejemplar "A", corresponde al lado derecho y el "B" al izquierdo. Tanto en una pieza como en la otra es posible observar una pequeña porción del canal mandibular que tiene mayor longitud en la correspondiente al lado izquierdo.

\section{CONCLUSIONES PARCIALES PARA EL ESTUDIO ANTROPOLÓGICO Y FORENSE DEL MATRERIAL:}

1. Todo el material óseo que aparece en la Gruta de los Huesos, está fragmentado incluyendo algunas piezas dentales, lo que muestra que los restos fueron intencionalmente tratados así, para producir el enterramiento, que debió responder a un ritual hasta ahora no reportado en la bibliografía sobre ritos funerarios en el país.

2. Que debido a la fragmentación, de 1386 fragmentos, sólo pudieron clasificarse 187 , lo que significa el $13.4 \%$ del total y de estos pudo tomarse determinaciones en solo 5 elementos que brindaron algún dato referente a sexo, edad o un mismo individuo.

3. La clasificación de los dientes para determinar el número de individuos representados en el entierro permitió establecer en 23 piezas 11 individuos por el método 
directo y 17 según el método indirecto, para una subestimación de 28 individuos (según relación promedio), lo que muestra dos aspectos de suma importancia en el estudio arqueológico:

a) Se trata de un enterramiento múltiple en que aparecen representados individuos de todas las etapas de la vida, desde lactantes hasta adultos.

b) Que la desrelación entre la determinación de individuos por las piezas dentales y el material óseo, muestra el hecho de que el material fue recogido arbitrariamente de algún cementerio aborigen para depositarlo allí, sin tener en cuenta representatividad de individuos, sino una especie de ofrenda con restos humanos.

Estos materiales aparecieron en la superficie (somos del criterio de que, a excepción del material de sílex que si debió ser depositado allí intencionalmente) el resto, no formaron parte del enterramiento.

\section{CONCLUSIONES GENERALES}

La prospección arqueológica, demostró que los restos fueron llevados al lugar desde áreas bien distantes (imaginamos que desde los actuales Cayos de Piedra que se visualizan desde el lugar) del sitio de enterramiento, por cuanto no existen evidencias de asentamientos aborígenes en la zona.

Todo el material óseo que aparece en la Gruta de los Huesos, está fragmentado incluyendo las piezas dentales, lo que muestra que los restos fueron intencionalmente tratados así, que debió responder a un ritual hasta ahora no reportado en la bibliografía sobre ritos funerarios en el país.

Que debido a la rotura de 1386 fragmentos, sólo pudieron clasificarse 187, lo que significa el $13.4 \%$ del total y de estos, pudo tomarse determinaciones en solo 5 elementos que brindaron algún dato referente a sexo, edad o un mismo individuo.

La clasificación de los dientes para determinar el número de individuos representados en el entierro permitió comprobar en 23 piezas, 11 individuos por el método directo y 17 según el método indirecto, para una subestimación de 28 individuos (según relación promedio), lo que muestra dos aspectos de suma importancia en el estudio arqueológico. Además, se evidenció que se trata de un enterramiento múltiple en que aparecen representados individuos de todas las etapas de la vida, desde lactantes hasta adultos y que la desrelación entre la determinación de individuos por las piezas dentales y el material óseo, muestra el hecho de que el material fue recogido arbitrariamente de 
diferentes cementerios aborígenes para depositarlos allí, sin tener en cuenta representatividad de individuos, sino una especie de ofrenda con restos humanos a un tipo de Deidad o Adoratorio (ello le brinda mucha importancia a la figura pétrea).

Por las características de dieta que se detecta en diferentes individuos según los estudios de traza en dientes, es evidente que el enterramiento "residual" respondió a restos humanos de diferentes zonas del territorio y diferentes estadios de desarrollo y antigüedad. Por lo tanto, no queda duda de que este recinto pétreo, constituyó un Adoratorio para los aborígenes que poblaron Yaguajay, al que ofrendaron con restos humanos de todas las edades fracturados lo que aun constituye un enigma para la ciencia porque no se repite en Cuba, en tal magnitud.

Por fin, los resultados de la investigación resultan un nuevo aporte a la Arqueología cubana y al conocimiento y desarrollo local para Yaguajay y que por su relevancia, necesita mantener su continuidad.

\section{REFERÊNCIAS}

COLECTIVO DE AUTORES. Cuevas y Carsos. Editorial Militar, La Habana, 1981.

CHILDE, Vere G. La evolución de la sociedad. Editorial Ciencias Sociales, La Habana. 1970.

CHIRINO, José Camacho E. et al. Estudio Geográfico Integral del Municipio Yaguajay, Provincia Sancti Spíritus, Cuba. Geocuba y CITMA. T-I.1996.

CHIRINO, José Camacho E. Los ritos funerarios en las culturas aborígenes de Cuba. [inédito]. Archivo del autor. 1998.

. Arqueología aborigen del Norte de la Provincia de Sancti Spíritus, Cuba. Ediciones Luminaria. 2010.

DE LAS CASAS, Bartolomé, Apologética historia de Las Indias. Nueva Biblioteca de Autores Españoles, No. 15, Madrid.1909.

DE LA TORRE, Juan, Testimonio del Escribano Juan de la Torre, "de los indios repartidos por Gonzalo Guzmán desde el 25 de abril hasta la fecha", Legajo Indiferente General 1203, No.23, Documentos Inéditos, Archivo General de Indias, Sevilla, España. 1530.

DOMÍNGUEZ, Lourdes S.; FEBLES, Jorge; RIVES Alexis V. Sugerencias para el tratamiento del período comunidades aborígenes de Cuba. En el desarrollo de la investigación de las historias locales, Instituto de Historia, La Habana.1990.

. Las comunidades aborígenes de Cuba. En Historia de Cuba. La Colonia: Evolución socioeconómica y formación nacional, Editora Política, La Habana. 1994. 
HERRERA FRITOT, René. Serie espeleológica y carsológica \#27: Arqueología espeleológica de Cuba, Academia de Ciencias de Cuba. 1970.

MARTÍNEZ-FORTÚN, José Foyo, A. Reseña histórica del territorio municipal de Yaguajay. Imprenta Pérez Sierra y Cía, La Habana. 1930.

PANÉ, Ramón. Relación acerca de las antigüedades de los indios. Editorial Ciencias Sociales, La Habana. 1990.

TABÍO, Ernesto; ESTRELlA Rey. Prehistoria de Cuba. Academia de Ciencias, La Habana, 2ed. 1979.

TABÍO, Ernesto. Introducción a la arqueología de las Antillas. Editorial Ciencias Sociales, La Habana. 1988.

VEGA SALADRIGAS, Rolando. Determinación de elementos traza en dientes de aborígenes cubanos mediante espectrometría de absorción atómica para establecer fuentes alimentarias. 2014. 84f. Tesis de Grado en Química) - Universidad Central "Marta Abreu" de Las Villas, Vila Clara. Facultad de Química Farmacia. Departamento de Licenciatura en Química. Villa Clara, Cuba. 2014.

\section{AGRADECIMIENTOS:}

- Al campesino Alberto Marichal Cáceres, quien nos sirvió de guía el 23 de octubre de 1968, cuando descubrimos el sitio.

- A la Dra. Belkis Baños Castellón por su asesoramiento en la clasificación preliminar de las piezas dentales.

- A lo Dr. C. Paleontólogo Físico: Manuel Rivero de La Calle, Profesor Facultad de Biología de la Universidad de la Habana (in memorian).

- A lo Dr. C. Odontólogo forense: Luis R. Toribio Suárez, Profesor Facultad de Biología de la Universidad de la Habana (in memorian).

- A La Facultad de Química de la Universidad Martha Abreu de Santa Clara por sus estudios de trazas en dientes.

- A los que colaboraron en las prospecciones de campo y excavaciones arqueológicas. 